Notre Dame Journal of Formal Logic

Volume XI, Number 1, January 1970

\title{
A NOTE ON PRIMARY AND SECONDARY SYNCATEGOREMATA
}

\author{
DOUGLAS DORROUGH
}

A favorite technique of Quine [1] for distinguishing the categorematic from the syncategorematic use of adjectives is to resolve linguistic compounds denoted by 'is (are) a _ _ so and so' into ones denoted by 'is (are) _. and is a so and so'). It is instructive to note that the grammatical susceptibility to this kind of resolution on the part of adjectival expressions can be extended in such a way as to establish a syntactical "heirarchy" of the adjectival syncategoremata of a given language (in this case English).

We previously used the expression "grammatical susceptibility" with good reason. For, while Quine would object to resolving the expression 1) 'big butterfly' into 2) 'is a butterfly and is big' [2], such a resolution is not grammatically discordant; whereas, the resolution of 3) 'each butterfly' into 4) 'is a butterfly and is each' is unquestionably illicit grammar. In this respect, we should like to state: A) There are adjectives which sometimes function syncategorematically and yet are frequently found to be a part of those terms which admit of resolution 2 ; B) there are adjectives which function syncategorematically but are never a part of terms admitting of resolution 2; and finally, C) adjectives of set $A$ will be called "Secondary" and those of set $B$, "Primary".

Thus, the adjective 'poor' in 5) 'poor sport' is used syncategorematically, since 5 cannot be resolved into 6) 'is a sport and is poor'. But the same adjective in 7) 'poor nation' functions quite differently, since 7 can be grammatically resolved into 8) 'is a nation and is poor.' On the other hand, although 'mere' in say 9) 'mere child' functions syncategorematically, there seem to be no examples of its use analogous to 7, i.e., no examples of a categorematic employment. Hence, 'mere' would be regarded as a primary syncategoreme while 'poor' would be assigned to the class of secondary syncategoremata.

Consideration of such indefinite singular terms as 10) 'Any poem' and 11) 'Every poem' alike reveals the absurdity of the translation into 12) 'is a poem and is any (every)'. Consequently, 'Any' and 'Every' seem to have the same status of primary syncategoremata. And there seem to be no 
examples to confute this conclusion. However, suppose the words 'All' and 'Many' in the expressions 13) 'All wives' and 14) 'Many wives' are compared. Clearly, 14 can be translated into 15) 'are wives and are many (i.e., are numerous), whereas 13 cannot be so translated. Therefore, we are encouraged to assign membership in the class of primary syncategoremata to 'All' while assigning membership in the class of secondary syncategoremata to 'Many'. Further, a similar comparison of 'Some' and 'Few' leads to an analogous assignment of membership.

Pursuit of this technique results in the following distinct, but by no means exhaustive, lists of quantificationally employed expressions:

$\begin{array}{lll}\text { Primary } & & \text { Secondary } \\ \text { All } & & \text { Many } \\ \text { Every } & & \text { Few } \\ \text { Any } & & \text { Frequent } \\ \text { Most } & \text { Scanty } \\ \text { Several } & \text { Poor } \\ \text { Some } & \text { Brief } \\ \text { Each } & \text { Seldom } \\ \text { The } & \text { Extensive } \\ \text { None } & \text { etc. } \\ \text { Bare } & \\ \text { Never } & \\ \text { etc. } & \end{array}$

Apart from the general difficulties (and they are many) with such a grammatical approach to syntactical insights, it is significant to note that classical Greek closely parallels English with respect to the grammatical distinction between primary and secondary syncategoremta. It is interesting, therefore, to speculate about Aristotle's emphasis in his logic on the role of such quantifiers as 'All' and 'Some', especially since so many of the members of the secondary list can, under suitable context, be translated into those of the primary list while the converse is not the case.

Finally, adverbial cognates of the words on our two lists might be quite germane to the further development of the already burgeoning field of tense logic.

\section{NOTES}

1. W. V. Quine, "Logic as a Source of Syntactical Insights," Structure of Language and Its Mathematical Aspects. Providence: American Mathematical Society, 1961. Cf. "Variables Explained Away," Proceedings of the American Philosophical Society, vol. 104 (1960). This technique is actually due to Frege, Begriffschrift. Jena, 1879.

2. The basis for such an objection is that 'big' does not denote an absolute attribute but rather is eliptical for a more complex relational expression. But this is clearly a logico-epistemological objection and not a grammatical one. 